\title{
Associations Between Methotrexate Use and the Risk of Cardiovascular Events in Patients with Elderly-onset Rheumatoid Arthritis
}

\author{
Jessica Widdifield (10), Michal Abrahamowicz (10), J. Michael Paterson (1), Anjie Huang (1),

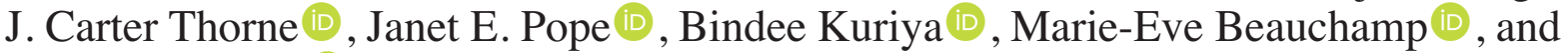 \\ Sasha Bernatsky
}

\begin{abstract}
Objective. We evaluated the associations between time-varying methotrexate (MTX) use and risk of cardiovascular events (CVE) in patients with rheumatoid arthritis (RA).

Methods. We studied an inception cohort of 23,994 patients with RA diagnosed after their 65th birthday. Multivariable Cox regression models were fit to evaluate the associations between time-varying MTX use, controlling for other risk factors, and time to CVE. Alternative models assessed the cumulative duration of MTX use over the (1) first year, (2) previous year (recent use), and (3) entire duration of followup. We also assessed whether the strength of the association varied over time.

Results. Over 115,453 patient-years (PY), 3294 (13.7\%) patients experienced a CVE (28.5 events per 1000 PY; 95\% CI 27.6-29.5). In the multivariable analyses, the model assessing time-varying continuous use in the most recent year yielded the best fit. Increasing recent MTX use was associated with lower CVE risks (HR 0.79 for continuous use vs no use in past 12 months, 95\% CI 0.70-0.88; $\mathrm{p}<0.0001$ ). Greater MTX use in the first year after cohort entry was also protective (HR $0.84,95 \%$ CI $0.72-0.96 ; p=0.0048)$, but this effect decreased with increasing followup. In contrast, longer MTX use during the entire followup was not clearly associated with CVE risk (HR 0.98, 95\% CI $0.95-1.01 ; \mathrm{p}=0.1441)$.
\end{abstract}

Conclusion. We observed about a 20\% decrease in CVE associated with recent continuous MTX use. Greater MTX use in the first year of cohort entry also appeared to be important in the association between MTX and CVE risk. (First Release December 1 2018; J Rheumatol 2019;46:467-74; doi:10.3899/jrheum.180427)

Key Indexing Terms:

RHEUMATOID ARTHRITIS

METHOTREXATE

CARDIOVASCULAR DISEASE DISEASE-MODIFYING ANTIRHEUMATIC DRUGS

From the Sunnybrook Research Institute, Holland Bone and Joint Research Program, Toronto, Ontario; Mc Gill University, Department of Epidemiology, Biostatistics and Occupational Health; Research Institute of the McGill University Health Centre, Department of Clinical Epidemiology, and Centre for Outcomes Research and Evaluation, Montreal, Quebec; ICES; University of Toronto, Institute of Health Policy, Management and Evaluation, Toronto; McMaster University, Department of Family Medicine, Hamilton; Southlake Regional Health Centre, Department of Medicine, Newmarket; Western University, Department of Epidemiology and Biostatistics; St. Joseph's Health Care, Department of Medicine, London; Mount Sinai Hospital, Department of Medicine, Toronto, Ontario, Canada.

This analysis was supported by the Canadian Network for Advanced Interdisciplinary Methods for comparative effectiveness research, which is funded by the Canadian Institutes of Health Research Drug Safety and Effectiveness Network (funding reference no. TD3-137716). JW was supported by fellowship awards from The Arthritis Society and the Canadian Institutes of Health Research (Banting) during the course of this work; SB holds a career award from the Fonds de la recherche en santé du Québec; MA is a James McGill Professor of Biostatistics at McGill University. This study was supported by the ICES, a nonprofit research corporation funded by the Ontario Ministry of Health and Long-Term Care. Parts of this material are based on data and/or information compiled and provided by the Canadian Institutes of Health Information (CIHI). However, the analyses, conclusions, opinions, and statements expressed in the material are those of the authors and not necessarily those of CIHI.
J. Widdifield, PhD, Sunnybrook Research Institute, Holland Bone and Joint Research Program, and McGill University, Department of Epidemiology, Biostatistics and Occupational Health, and Research Institute of the McGill University Health Centre, Department of Clinical Epidemiology, ICES, and University of Toronto, Institute of Health Policy, Management and Evaluation; M. Abrahamowicz, PhD, McGill University, Department of Epidemiology, Biostatistics and Occupational Health, and Research Institute of the McGill University Health Centre, Centre for Outcomes Research and Evaluation; J.M. Paterson, MSc, ICES, and University of Toronto, Institute of Health Policy, Management and Evaluation, and McMaster University, Department of Family Medicine; A. Huang, MSc, ICES; J.C. Thorne, MD, FRCPC, Southlake Regional Health Centre, Department of Medicine; J.E. Pope, MD, FRCPC, MPH, Western University, Department of Epidemiology and Biostatistics, and St. Joseph's Health Care, Department of Medicine; B. Kuriya, MD, FRCPC, SM, Mount Sinai Hospital, Department of Medicine; M.E. Beauchamp, $P h D$, Research Institute of the McGill University Health Centre, Centre for Outcomes Research and Evaluation; S. Bernatsky, MD, FRCPC, PhD, McGill University, Department of Epidemiology, Biostatistics and Occupational Health, and Research Institute of the McGill University Health Centre, Centre for Outcomes Research and Evaluation.

Address correspondence J. Widdifield, Holland Bone and Joint Research Program, Sunnybrook Research Institute MG 352, 2075 Bayview Ave., Toronto, Ontario M4N 3M5, Canada. E-mail: jessica.widdifield@utoronto.ca

Accepted for publication August 22, 2018.

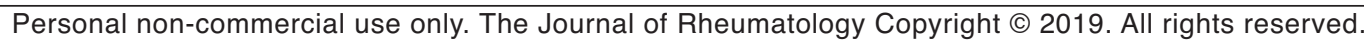


High cardiovascular morbidity is an unfortunate reality in rheumatoid arthritis (RA) $)^{1,2,3,4,5,6}$. Chronic high-grade systemic inflammation has been implicated in promoting atherogenesis and increased cardiovascular morbidity $7,8,9,10$. Thus, conventional synthetic disease-modifying antirheumatic drugs (csDMARD), which target inflammation, could influence atherogenesis and therefore cardiovascular risk in patients with RA.

A metaanalysis of 8 studies reported a $28 \%$ reduction in the risk of cardiovascular events (CVE) associated with methotrexate (MTX) use in patients with RA (RR 0.72, 95\% CI $0.57-0.91)^{11}$. However, many of the underlying studies were heterogeneous and failed to account for the duration or timing of treatment exposure; rather MTX exposure was defined as a binary indicator of ever/never use, current use, or a baseline covariate ${ }^{12,13}$. In clinical practice, duration and timing of exposure to MTX and other csDMARD varies considerably within and among individual patients over time $^{14}$. The potential beneficial effects of MTX and other csDMARD also may vary over time. For example, patients with greater early MTX use may require less MTX later. Conversely, some patients may use MTX in a consistent manner throughout their disease course, but initiate late, and the therapeutic window of opportunity may be missed ${ }^{15}$. Thus, patients with early intensive treatment and/or those who recently had persistent use of MTX will have a greater likelihood of obtaining a low disease activity state ${ }^{16}$ and thereby reducing systemic inflammation, which could offer greater potential for reducing CVE risk ${ }^{17}$.

Our aim was to assess the associations between time-varying use of MTX and other csDMARD and CVE risk to determine whether the effects vary by timing, recency, and duration of use, and whether effects vary over time.

\section{MATERIALS AND METHODS}

Study design. Using health administrative data in Ontario, Canada, we studied an inception cohort of patients with RA to examine the effects of time-varying RA treatment, controlling for other risk factors, on the risk of CVE. Our analyses were confined to persons aged 66 years or older for whom we had complete prescription drug histories (because the age cutoff for public drug coverage is 65 years and older; however, there may be delays in transitioning into public drug coverage).

Data sources. We used the Ontario Health Insurance Plan (OHIP) Claims History Database to identify diagnoses and procedures associated with physician services. We identified patient demographic information and vital status from the OHIP Registered Persons Database. Medication exposures were determined using the pharmacy claims database of the Ontario Drug Benefit Program. Hospital admissions and procedures were identified using the Canadian Institute for Health Information Discharge Abstract Database. These datasets are held securely in a linked coded form at the ICES. The study was authorized under section 45 of Ontario's Personal Health Information Protection Act, which means it did not require approval by a research ethics board.

Cohort selection. We identified patients with RA within the Ontario Rheumatoid Arthritis Dataset ${ }^{18}$. Our analyses were confined to individuals who had at least 3 physician service claims with an RA diagnosis (with at least 1 provided by a musculoskeletal specialist) within 2 years. This algorithm has about $80 \%$ sensitivity and positive predictive value for physician-diagnosed $\mathrm{RA}^{19}$. We defined the cohort entry date as the date when all criteria were met. Patients were required to be newly diagnosed after their 66th birthday (to ensure complete medication records after disease onset) between January 1, 2000, and March 1, 2013. Thus, patients were excluded if they had RA prior to their 66th birthday. Patients were excluded if they had missing demographic information, or were hospitalized or dead on the cohort entry date.

Outcome. The primary study outcome was a composite endpoint defined as the incidence of hospitalization for acute myocardial infarction (AMI), stroke, or congestive heart failure, or either percutaneous coronary intervention or coronary artery bypass graft surgery. Diagnosis and procedure codes (Supplementary Table 1, available with the online version of this article) used to define these events have been validated in Ontario and deemed to have a high specificity $20,21,22,23,24$.

Time-dependent medication exposures. The main exposures of interest were MTX and other csDMARD (azathioprine, sulfasalazine, gold, chloroquine, hydroxychloroquine, leflunomide, cyclosporine, minocycline, penicillamine, myochrysine, and cyclophosphamide), with nonuse as the referent category. We constructed a daily medication exposure matrix for each patient, incorporating each prescription start date, number of pills, dosage, and days supplied $^{25}$. On this basis, we calculated a time-dependent, daily measure of cumulative duration of use of a specific medication, or class of medications, until a given day during the followup period ${ }^{26}$. The following assumptions were applied: for overlapping prescriptions of the same drug, we assumed the individual to have refilled early and completed the first prescription before starting the second. The same rule was applied to overlapping prescriptions of the same medication but with different doses and overlapping prescriptions for different medications within the same medication class. For combination use of csDMARD, prescriptions for each class of csDMARD were treated separately. When there was a gap of 7 days or fewer between 2 prescriptions of the same medication, or of different medications within the same class (excluding csDMARD), it was assumed that the medication was taken continuously and the gap was filled with the daily dose of the second prescription.

Using the same method, we also adjusted for time-varying cumulative duration of use of other medications since cohort entry: anti-tumor necrosis factor (anti-TNF) inhibitors, other biologic DMARD, cyclooxygenase-2 inhibitors (COXIB), nonselective nonsteroidal antiinflammatory drugs (NSAID), systemic glucocorticosteroids, statins, and antihypertensives.

Baseline medication exposures. We also identified binary time-invariant indicators of baseline exposures to MTX, other csDMARD, anti-TNF inhibitors, COXIB, NSAID, glucocorticosteroids, statins, and antihypertensives, defined as any prescription for the corresponding medication during the 1 year prior to cohort entry.

Other covariates. Potential risk factors and confounders for the association between the medications of interest and CVE were selected a priori. Sociodemographic variables included sex, age at cohort entry (in years and with a squared-age term added to account for nonlinear effects), place of residence (urban or rural, defined from postal codes), and regional socioeconomic status (income quintiles derived from census data). Baseline comorbidity was based on the 3 years prior to cohort entry, using diagnosis codes from all outpatient and hospital visits, and included hypertension, diabetes, cerebrovascular disease, acute renal failure, chronic kidney disease, prior AMI, coronary artery disease, chronic obstructive pulmonary disease or asthma, cancer, osteoarthritis, and prior joint replacement surgery (Supplementary Table 2, available with the online version of this article). To adjust for severity of baseline illness, we used the Johns Hopkins ACG System (version 10) case-mix adjustment system. To discriminate between higher and lower users of the healthcare system, we adjusted for a binary indicator of high use, defined as at least 20 physician visits during at least 1 year of the 3 years before baseline. As proxies for disease severity ${ }^{27}$, we used a time-varying number of rheumatologist visits (log-transformed because of a skewed distribution) and time-varying indicators for the development of extraarticular RA manifestations, including lung involvement (pleurisy, pulmonary fibrosis, rheumatoid lung, interstitial lung disease),

Personal non-commercial use only. The Journal of Rheumatology Copyright (C) 2019. All rights reserved. 
hematological involvement (Felty syndrome), cardiac involvement (rheumatic carditis, endocarditis, myocarditis, pericarditis), eye involvement (scleritis, keratoconjunctivitis), dermatological complications (vasculitis, pyoderma gangrenosum), entrapment syndromes, neuropathies, and amyloidosis.

Statistical analysis. All primary analyses relied on time-to-event methodology. Time-to-event was defined as time from cohort entry to CVE. Subjects who had no CVE during followup were censored at the earliest of the dates of emigration, non-CVE death, or the end of the study period (December 31, 2015). The CVE incidence rate was estimated using the total person-time accumulated from cohort entry as the denominator.

Three separate time-dependent multivariable Cox proportional hazards models were fit to estimate adjusted HR and 95\% CI for the associations between model-specific time-varying measures of the cumulative past duration of RA medication exposures and time to CVE. All models estimated separate, mutually adjusted associations with MTX and other csDMARD, and controlled for all aforementioned covariates.

Model A assessed the cumulative duration of use of MTX, and other csDMARD, in the first year after cohort entry only. These exposure measures were updated during the first year and then kept constant for the rest of followup. For Model B, the exposure, at any timepoint in the followup, was defined as the cumulative use in the past 12 months. Finally, Model C assessed the cumulative duration of past use since cohort entry. In models B and $\mathrm{C}$, exposures were continuously updated during the followup. We compared the Akaike information criterion (AIC) values for the alternative exposure models, with a reduction in AIC of 4 points or more indicating an improved model fit ${ }^{28}$.

For each model, the proportional hazards assumption was assessed by testing the time-varying interaction between MTX use and followup time ${ }^{29}$. A statistically nonsignificant interaction ( $p>0.05)$ was interpreted as lack of evidence that the strength of the association varies with followup ${ }^{29}$.

In sensitivity analyses, all 3 models were expanded to include an interaction term between the corresponding measures of the cumulative effects of MTX and other csDMARD. The interaction was tested to determine whether the associations of interest differed depending on the use of the other medication class (MTX and csDMARD categories), and was removed from the final model if not statistically significant at $\alpha=0.05$ for a 2-tailed model-based Wald test ${ }^{30}$.

In a final sensitivity analysis, we excluded patients who had preexisting coronary artery disease or cerebrovascular disease prior to cohort entry.

All analyses were performed using SAS Enterprise Guide 6.1.

\section{RESULTS}

A schematic representation of the cohort selection is detailed in Figure 1.

Among 23,994 incident patients with RA, two-thirds were female $(67 \%)$ and mean age was 75 years. Patients had a high CVE risk burden at cohort entry (70\% had preexisting hypertension, $23 \%$ diabetes, $16 \%$ coronary artery disease, $3 \%$ previous AMI, and 1\% cerebrovascular disease; Table 1). Within the year prior to cohort entry, immune-modulating drug use included glucocorticosteroids (57\%), other csDMARD (36\%), and MTX (32\%). During followup, 50\% of patients had at least 1 prescription for MTX, 54\% for other csDMARD, and $68 \%$ for glucocorticosteroids (Table 2).

During the total of 115,453 patient-years (PY) of followup, 3294 patients (13.7\%) experienced a CVE (28.5 events per 1000 PY; 95\% CI 27.6-29.5).

In the adjusted multivariable analyses, Model B assessing time-varying duration of use in the most recent year of followup yielded the best fit (lowest AIC, Table 3).
Continuous MTX use in the past 12 months was associated with 20\% CVE risk reduction (adjusted HR 0.79, 95\% CI $0.70-0.88, \mathrm{p}<0.0001$ ) relative to those who did not use any MTX in the past year (Table 3). This association was reasonably constant over followup ( $\mathrm{p}=0.086$ for testing the proportional hazards hypothesis), with a minor trend to become weaker over time (data not shown).

In Model A, early MTX use, in the first year after cohort entry, was also protective (HR $0.84,95 \%$ CI $0.72-0.96$, for full year of use vs no use, $p=0.005$ ), but a statistically significant interaction with time suggested this effect weakens with increasing followup duration ( $\mathrm{p}=0.033)$.

In contrast, in Model $\mathrm{C}$ greater cumulative duration of past MTX use since cohort entry had no association with CVE risk (HR 0.98, 95\% CI 0.95-1.01 for each additional year of past use, $\mathrm{p}=0.144$ ), and this model yielded the worst fit to data (Table 3).

In all 3 models, the different time-varying exposures for other csDMARD were not systematically associated with CVE risks (Table 3).

Sensitivity analyses identified no statistically significant interactions between corresponding exposures to the 2 classes of medications, indicating that the beneficial effects of MTX use did not vary depending on whether the patient used other csDMARD (all interaction $p$ values $>0.27$ ).

In the best-fitting multivariable analysis (Model B), longer duration of past use since cohort entry was associated with a lower CVE risk for statins (HR 0.96 per each additional year of use, 95\% CI 0.94-0.98; Table 4), but with an increased risk for glucocorticosteroids (HR 1.08 per additional year of use, 95\% CI 1.05-1.11). We did not detect an association with CVE risk related to greater use of anti-TNF during followup (HR 1.02 per additional year of use, 95\% CI 0.94-1.12), likely due to the small number of anti-TNF users. The strongest independent risk factors for a major CVE were preexisting comorbidities at time of RA diagnosis (Table 4).

A sensitivity analysis involving 19,942 patients with RA without prior cardiovascular disease at cohort entry (Figure 1) produced results similar to those in the primary analysis (Supplementary Table 3, available with the online version of this article).

\section{DISCUSSION}

In this large population-based inception RA cohort, we used alternative time-varying exposures to examine the associations between MTX use (and other csDMARD) and risk of CVE. This allowed us to assess whether the effects varied by timing, recency, and duration of medication use, and whether the observed associations were sustained over time.

In our sample, we observed about a $20 \%$ decrease in CVE risk associated with recent (past 12 mos) continuous MTX use. This effect slightly weakened later in followup, suggesting that the observed effects may be strongest in the

$$
\text { Personal non-commercial use only. The Journal of Rheumatology Copyright (C) 2019. All rights reserved. }
$$




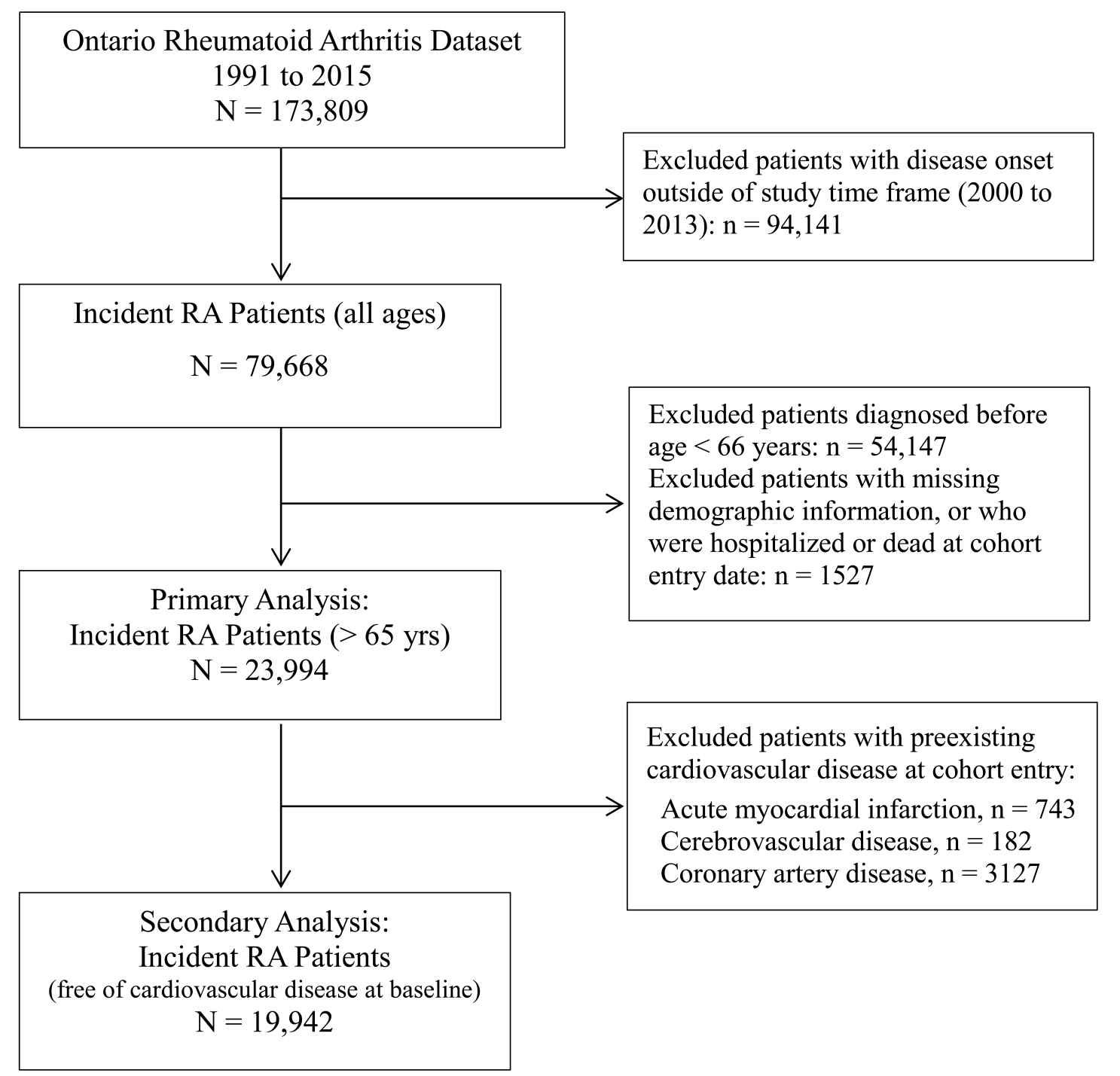

Figure 1. Schematic representation of the process used to select patients for inclusion in the final cohort. RA: rheumatoid arthritis.

early phase of RA. We were unable to show an association of decreased events with greater cumulative MTX duration from the cohort entry to a current timepoint during followup. This suggests that patients may have to continue MTX throughout followup to maintain a decreased CVE risk. Further, first-year use also having a statistically significant association may suggest that a window of opportunity may be missed if MTX is not used early in the disease course. Because there is evidence that aggressive treatment soon after RA onset increases the chance of csDMARD-free remission ${ }^{15}$, these individuals subsequently may have less cumulative MTX or other csDMARD use throughout their entire disease course. The potential risk of high homocysteine levels and other adverse effects associated with chronic MTX use in some patients $^{31,32}$ are also potential explanations for the weaker associations between MTX and CVE risk later in followup.
Our findings are compatible with a metaanalysis that estimated that MTX in RA was associated with $28 \%$ lower CVE risk, although the underlying studies were heterogeneous ${ }^{11}$. However, our methods were specifically designed to account for the time-varying nature of RA medication use, in contrast to previous studies, which mostly defined treatment use in a time-invariant manner ${ }^{12,13}$. Indeed, a systematic review reported that over $40 \%$ of the reviewed studies ignored the presence of time-varying exposures in the analyses ${ }^{33}$. However, in clinical practice, especially in chronic diseases such as RA, medication use is often time-variant, because treatment is frequently initiated at different intervals during a patient's disease course and may be interrupted and/or reinitiated at some later time(s). Thus, our study fills an important gap in the literature because prior studies may have overestimated the treatment effect size or 
Table 1. Baseline characteristics of 23,994 incident patients with RA.

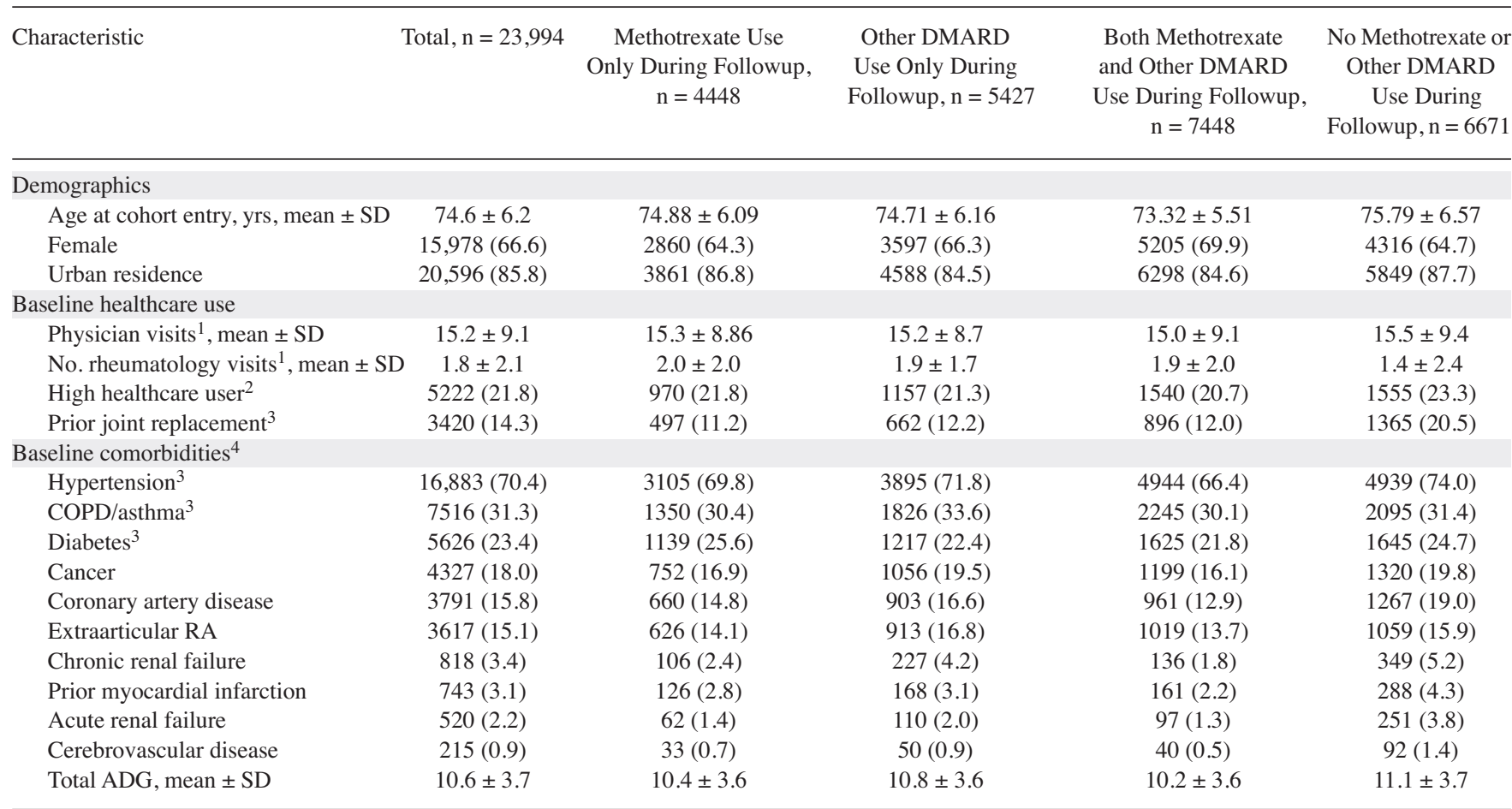

Data are $\mathrm{n}(\%)$ unless otherwise specified. ${ }^{1}$ Ascertained over the 1 year prior to baseline. ${ }^{2}$ Defined by having at least 20 outpatient physician visits in at least 1 year of the 3 years before baseline. ${ }^{3}$ Ascertained over all available years prior to baseline. ${ }^{4}$ Ascertained over the 3 years prior to baseline unless otherwise stated. RA: rheumatoid arthritis; DMARD: disease-modifying antirheumatic drug; ADG: aggregated diagnosis groups; COPD: chronic obstructive pulmonary disease.

Table 2. Baseline and followup medication exposures.

\begin{tabular}{lc}
\hline Baseline medication exposures $^{1}$ & \\
Methotrexate & $7694(32.1)$ \\
Other DMARD & $8562(35.7)$ \\
Glucocorticosteroids & $13,758(57.3)$ \\
COXIB & $9725(40.5)$ \\
NSAID & $8963(37.4)$ \\
Antihypertensive agents & $15,247(63.5)$ \\
Statins & $9334(38.9)$ \\
Followup medication exposures ${ }^{2}$ & \\
Methotrexate & $11,896(49.6)$ \\
Other DMARD & $12,875(53.7)$ \\
Glucocorticosteroids & $16,247(67.7)$ \\
COXIB & $10,065(41.9)$ \\
NSAID & $8491(35.4)$ \\
Anti-TNF & $1015(4.2)$ \\
Other bDMARD & $192(0.8)$ \\
Antihypertensive agents & $18,543(77.3)$ \\
Statins & $11,868(49.5)$ \\
\hline
\end{tabular}

Data are $\mathrm{n}(\%) .{ }^{1}$ Ascertained over the 1 year prior to cohort entry. 2 Proportion of patients with at least 1 prescription during followup. DMARD: disease-modifying antirheumatic drugs; bDMARD: biologic DMARD; COXIB: cyclooxygenase-2 inhibitors; NSAID: nonsteroidal antiinflammatory drug; TNF: tumor necrosis factor.

increased the risk of type II error (failure to detect a true association $)^{28,34}$.

We found that preexisting comorbidities and glucocorticosteroids are associated with increased CVE risk, while statins were associated with a reduced risk. There is an accumulating body of evidence to support the use of statins for primary prevention of CVE in RA ${ }^{35,36,37}$. Statins not only provide a cholesterol-reducing effect in RA similar to those without $\mathrm{RA}^{38,39}$, they may also have some antiinflammatory and immunomodulatory properties that could attenuate RA-related inflammation and disease activity ${ }^{40,41}$. Whether all patients with RA would benefit from treatment with statins, irrespective of lipid levels, still requires investigation $^{42}$.

Our study is unique, to our knowledge, in that it includes a large inception population-based RA cohort with detailed prescription data that enabled us to compare different time-varying treatment measures. However, several potential limitations warrant discussion. Evaluating the associations of RA treatments on CVE risk is difficult because greater medication use may be associated with more severe RA and the severity of RA may itself have effects on cardiovascular disease. Thus, similar to most other large administrative database studies of the effectiveness or safety of RA medications ${ }^{43,44,45}$, confounding by indication (or disease severity) cannot be ruled out, whereby MTX may be used less in patients with greater comorbidity (or lower disease activity) and/or those with a higher cardiovascular risk. Information on other potential confounders or effect modifiers, such as body mass index, physical activity, inflammatory markers, alcohol and tobacco use, folate supplementation, and

Personal non-commercial use only. The Journal of Rheumatology Copyright (C) 2019. All rights reserved. 
Table 3. Comparison of 3 different time-varying measures.

\begin{tabular}{|c|c|c|c|c|c|}
\hline Model $^{1}$ & & $\mathrm{HR}^{2}$ & $95 \% \mathrm{CI}$ & $\mathrm{p}$ & $\mathrm{AIC}^{3}$ \\
\hline \multirow[t]{2}{*}{ A } & Continuous use of MTX in first year only & 0.84 & $0.72-0.96$ & 0.0048 & 60532 \\
\hline & Continuous use of other csDMARD in first year only & 0.93 & $0.81-1.04$ & 0.2021 & \\
\hline B & Continuous use of other csDMARD in the past $12 \mathrm{mos}$ & 1.00 & $0.98-1.02$ & 0.9927 & \\
\hline \multirow[t]{2}{*}{$\mathrm{C}$} & Cumulative duration of use of MTX since cohort entry & 0.98 & $0.95-1.01$ & 0.1441 & 60539 \\
\hline & Cumulative duration of use of other csDMARD since cohort entry & 1.00 & $0.98-1.02$ & 0.8626 & \\
\hline
\end{tabular}

${ }^{1}$ Treatment effect estimates for 3 separate models assessing the time-varying measures of past duration of cumulative use during (A) the first year following cohort entry, (B) the previous 12 months (recent use), and (C) since cohort entry. ${ }^{2}$ Adjusted HR expressed as per year of use versus nonuse. ${ }^{3}$ AIC: Akaike information criterion, with lower values indicating better fit to data. MTX: methotrexate; csDMARD: conventional synthetic disease-modifying antirheumatic drugs.

over-the-counter acetylsalicylic acid and NSAID were not available to us. However, if MTX use was more frequent among patients with more severe RA, this would bias our results in the direction of higher estimated risks for users, and thus cannot explain the protective effects we found. Additionally, a recent analysis found no important differences in the distribution of these potential confounders across drug exposure categories (MTX vs other csDMARD $)^{46}$.

While our analysis was confined to RA onset at a later age, the incidence of RA increases with age ${ }^{47}$ and our sample is thus an important component of the entire RA population, and one at high risk of CVE. Admittedly, the presentation, treatment regimens, severity, and prognosis of RA may differ for patients diagnosed at later ages ${ }^{4,49,50}$ and these differences may influence the generalizability of our findings. Thus replication in other cohorts may be in order. In addition, accurate dates of symptom onset were not available to us in administrative data and some RA may not have been truly incident.

While our analysis included a composite outcome (to identify the first occurrence of cardiovascular disease) and the treatment effects may vary across these individual events, prior studies that have separated their composite outcome into separate endpoints found the risk estimates to be similar to those using the composite endpoint ${ }^{46}$.

Greater recent use of MTX, particularly early in the disease course, is associated with a decreased risk of CVE in elderly-onset RA. Our alternative time-varying analyses provide important insights into the associations of MTX and cardiovascular morbidity in RA. The timing of MTX initiation, recency and duration of use appeared to be important factors in the observed associations between MTX and CVE risk. Our epidemiological evidence supports clinical recommendations that patients with RA should initiate MTX treatment early, with appropriate continuation to control disease over time.

\section{ACKNOWLEDGMENT}

We thank Brogan Inc., Ottawa, for use of its Drug Product and Therapeutic Class Database.

\section{ONLINE SUPPLEMENT}

Supplementary material accompanies the online version of this article.

\section{REFERENCES}

1. Avina-Zubieta JA, Thomas J, Sadatsafavi M, Lehman AJ, Lacaille D. Risk of incident cardiovascular events in patients with rheumatoid arthritis: A meta-analysis of observational studies. Ann Rheum Dis 2012;71:1524-9.

2. Widdifield J, Paterson JM, Huang A, Bernatsky S. Causes of death in rheumatoid arthritis: How do they compare to the general population? Arthritis Care Res 2018 Mar 7 (E-pub ahead of print).

3. Boers M, Dijkmans B, Gabriel S, Maradit-Kremers H, O’Dell J, Pincus T. Making an impact on mortality in rheumatoid arthritis: targeting cardiovascular comorbidity. Arthritis Rheum 2004;50:1734-9.

4. Naranjo A, Sokka T, Descalzo MA, Calvo-Alén J, Hørslev-Petersen K, Luukkainen RK, et al; QUEST-RA Group. Cardiovascular disease in patients with rheumatoid arthritis: results from the QUEST-RA study. Arthritis Res Ther 2008;10:R30.

5. Solomon DH, Goodson NJ, Katz JN, Weinblatt ME, Avorn J, Setoguchi S, et al. Patterns of cardiovascular risk in rheumatoid arthritis. Ann Rheum Dis 2006;65:1608-12.

6. Mantel A, Holmqvist M, Jernberg T, Wallberg-Jonsson S, Askling J Rheumatoid arthritis is associated with a more severe presentation of acute coronary syndrome and worse short-term outcome. Eur Heart J 2015;36:3413-22.

7. Gonzalez-Gay MA, Gonzalez-Juanatey C, Martin J. Rheumatoid arthritis: A disease associated with accelerated atherogenesis. Semin Arthritis Rheum 2005;35:8-17.

8. Dessein PH, Norton GR, Woodiwiss AJ, Joffe BI, Wolfe F. Influence of nonclassical cardiovascular risk factors on the accuracy of predicting subclinical atherosclerosis in rheumatoid arthritis. J Rheumatol 2007;34:943-51.

9. Rodriguez-Rodriguez L, Lopez-Mejias R, Garcia-Bermudez M, Gonzalez-Juanatey C, Gonzalez-Gay MA, Martin J. Genetic markers of cardiovascular disease in rheumatoid arthritis. Mediators Inflamm 2012;2012:574817.

10. Sattar N, McCarey DW, Capell H, McInnes IB. Explaining how "high-grade" systemic inflammation accelerates vascular risk in rheumatoid arthritis. Circ Cardiovasc Qual Outcomes 2003;108:2957-63

11. Roubille C, Richer V, Starnino T, McCourt C, McFarlane A, Fleming $\mathrm{P}$, et al. The effects of tumour necrosis factor inhibitors, methotrexate, non-steroidal anti-inflammatory drugs and corticosteroids on cardiovascular events in rheumatoid arthritis, psoriasis and psoriatic arthritis: a systematic review and meta-analysis. Ann Rheum Dis 2015;74:480-9.

12. Micha R, Imamura F, Wyler von Ballmoos M, Solomon DH, Hernan

Personal non-commercial use only. The Journal of Rheumatology Copyright @ 2019. All rights reserved 
Table 4. Best-fitting multivariable model.

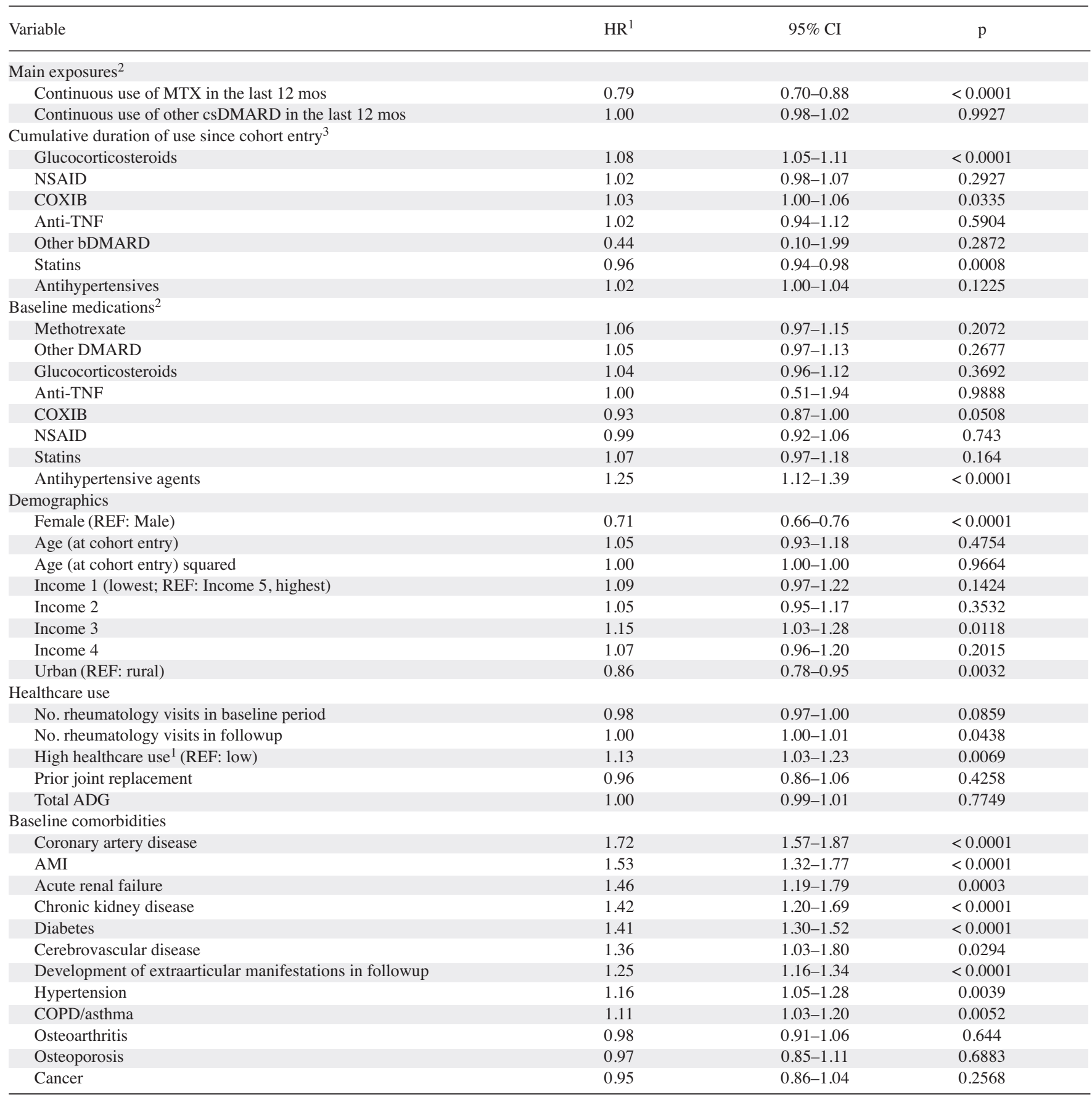

${ }^{1}$ Adjusted for all covariates. ${ }^{2}$ REF: nonuse over the same period as the numerator. ${ }^{3}$ HR expressed as per year of additional use. MTX: methotrexate; ADG: aggregated diagnosis groups; AMI: acute myocardial infarction; bDMARD: biologic disease-modifying antirheumatic drugs; COPD: chronic obstructive pulmonary disease; COXIB: cyclooxygenase inhibitors; csDMARD: conventional synthetic DMARD; NSAID: nonsteroidal antiinflammatory drug; TNF: tumor necrosis factor.

MA, Ridker PM, et al. Systematic review and meta-analysis of methotrexate use and risk of cardiovascular disease. Am J Cardiol 2011;108:1362-70.

13. Westlake SL, Colebatch AN, Baird J, Kiely P, Quinn M, Choy E, et al. The effect of methotrexate on cardiovascular disease in patients with rheumatoid arthritis: A systematic literature review.

Rheumatology 2010;49:295-307.
14. Curtis JR, Bykerk VP, Aassi M, Schiff M. Adherence and persistence with methotrexate in rheumatoid arthritis: a systematic review. J Rheumatol 2016;43:1997-2009.

15. van Nies JA, Krabben A, Schoones JW, Huizinga TW, Kloppenburg M, van der Helm-van Mil AH. What is the evidence for the presence of a therapeutic window of opportunity in rheumatoid arthritis? A systematic literature review. Ann Rheum Dis 2014;73:861-70. 
16. Stoffer MA, Schoels MM, Smolen JS, Aletaha D, Breedveld FC, Burmester G, et al. Evidence for treating rheumatoid arthritis to target: results of a systematic literature search update. Ann Rheum Dis 2016;75:16-22.

17. Marks JL, Edwards CJ. Protective effect of methotrexate in patients with rheumatoid arthritis and cardiovascular comorbidity. Ther Adv Musculoskelet Dis 2012;4:149-57.

18. Widdifield J, Bernatsky S, Bombardier C, Paterson M. Rheumatoid arthritis surveillance in Ontario: monitoring the burden, quality of care and patient outcomes through linkage of administrative health data. Healthc Q 2015;18:7-10.

19. Widdifield J, Bombardier C, Bernatsky S, Paterson JM, Green D, Young $\mathrm{J}$, et al. An administrative data validation study of the accuracy of algorithms for identifying rheumatoid arthritis: the influence of the reference standard on algorithm performance. BMC Musculoskelet Disord 2014;15:216.

20. Austin PC, Daly PA, Tu JV. A multicenter study of the coding accuracy of hospital discharge administrative data for patients admitted to cardiac care units in Ontario. Am Heart J 2002; 144:290-6.

21. Tu K, Wang M, Young J, Green D, Ivers NM, Butt D, et al. Validity of administrative data for identifying patients who have had a stroke or transient ischemic attack using emrald as a reference standard. Can J Cardiol 2013;29:1388-94.

22. Tu K, Mitiku T, Guo H, Lee DS, Tu JV. Myocardial infarction and the validation of physician billing and hospitalization data using electronic medical records. Chronic Dis Can 2010;30:141-6.

23. Lee DS, Stitt A, Wang X, Yu JS, Gurevich Y, Kingsbury KJ, et al. Administrative hospitalization database validation of cardiac procedure codes. Med Care 2013;51:e22-6.

24. Yeung DF, Boom NK, Guo H, Lee DS, Schultz SE, Tu JV. Trends in the incidence and outcomes of heart failure in Ontario, Canada: 1997 to 2007. CMAJ 2012;184:E765-73.

25. Abrahamowicz M, Tamblyn R. Drug utilization patterns. In: Armitage P, Colton T, editors. Encyclopedia of biostatistics. 2nd ed. Chichester: John Wiley \& Sons; 2005:1533-53.

26. Abrahamowicz M, Bartlett G, Tamblyn R, du Berger R. Modeling cumulative dose and exposure duration provided insights regarding the associations between benzodiazepines and injuries. J Clin Epidemiol 2006;59:393-403.

27. Vinet E, Kuriya B, Widdifield J, Bernatsky S. Rheumatoid arthritis disease severity indices in administrative databases: a systematic review. J Rheumatol 2011;38:2318-25.

28. Abrahamowicz M, Beauchamp ME, Sylvestre MP. Comparison of alternative models for linking drug exposure with adverse effects. Stat Med 2012;31:1014-30.

29. Abrahamowicz M, MacKenzie T, Esdaile JM. Time-dependent hazard ratio: modeling and hypothesis testing with application in lupus nephritis. J Am Stat Assoc 1996;91:1432-9.

30. Abrahamowicz M, Beauchamp ME, Fournier P, Dumont A. Evidence of subgroup-specific treatment effect in the absence of an overall effect: Is there really a contradiction? Pharmacoepidemiol Drug Saf 2013;22:1178-88.

31. Hoekstra M, Haagsma CJ, Doelman CJ, van de Laar MA. Intermittent rises in plasma homocysteine in patients with rheumatoid arthritis treated with higher dose methotrexate. Ann Rheum Dis 2005;64:141-3.

32. Salliot C, van der Heijde D. Long-term safety of methotrexate monotherapy in patients with rheumatoid arthritis: A systematic literature research. Ann Rheum Dis 2009;68:1100-4.

33. van Walraven C, Davis D, Forster AJ, Wells GA. Time-dependent bias was common in survival analyses published in leading clinical journals. J Clin Epidemiol 2004;57:672-82.

34. Pazzagli L, Linder M, Zhang M, Vago E, Stang P, Myers D, et al. Methods for time-varying exposure related problems in pharmacoepidemiology: An overview. Pharmacoepidemiol Drug Saf 2018;27:148-60.

35. Sheng X, Murphy MJ, Macdonald TM, Wei L. Effectiveness of statins on total cholesterol and cardiovascular disease and all-cause mortality in osteoarthritis and rheumatoid arthritis. J Rheumatol 2012;39:32-40.

36. De Vera MA, Choi H, Abrahamowicz M, Kopec J, Lacaille D. Impact of statin discontinuation on mortality in patients with rheumatoid arthritis: a population-based study. Arthritis Care Res 2012;64:809-16.

37. De Vera MA, Choi H, Abrahamowicz M, Kopec J, Goycochea-Robles MV, Lacaille D. Statin discontinuation and risk of acute myocardial infarction in patients with rheumatoid arthritis: a population-based cohort study. Ann Rheum Dis 2011;70:1020-4.

38. Semb AG, Kvien TK, DeMicco DA, Fayyad R, Wun CC, LaRosa $\mathrm{JC}$, et al. Effect of intensive lipid-lowering therapy on cardiovascular outcome in patients with and those without inflammatory joint disease. Arthritis Rheum 2012;64:2836-46.

39. Semb AG, Holme I, Kvien TK, Pedersen TR. Intensive lipid lowering in patients with rheumatoid arthritis and previous myocardial infarction: an explorative analysis from the incremental decrease in endpoints through aggressive lipid lowering (IDEAL) trial. Rheumatology 2011;50:324-9.

40. Abeles AM, Pillinger MH. Statins as antiinflammatory and immunomodulatory agents: a future in rheumatologic therapy? Arthritis Rheum 2006;54:393-407.

41. Lv S, Liu Y, Zou Z, Li F, Zhao S, Shi R, et al. The impact of statins therapy on disease activity and inflammatory factor in patients with rheumatoid arthritis: a meta-analysis. Clin Exp Rheumatol 2015;33:69-76.

42. Danninger K, Hoppe UC, Pieringer H. Do statins reduce the cardiovascular risk in patients with rheumatoid arthritis? Int J Rheum Dis 2014;17:606-11.

43. Yun H, Xie F, Delzell E, Chen L, Levitan EB, Lewis JD, et al. Risk of hospitalised infection in rheumatoid arthritis patients receiving biologics following a previous infection while on treatment with anti-TNF therapy. Ann Rheum Dis 2015;74:1065-71.

44. Solomon DH, Rassen JA, Kuriya B, Chen L, Harrold LR, Graham DJ, et al. Heart failure risk among patients with rheumatoid arthritis starting a TNF antagonist. Ann Rheum Dis 2013;72:1813-8.

45. Dixon WG, Kezouh A, Bernatsky S, Suissa S. The influence of systemic glucocorticoid therapy upon the risk of non-serious infection in older patients with rheumatoid arthritis: a nested case-control study. Ann Rheum Dis 2011;70:956-60.

46. Solomon DH, Avorn J, Katz JN, Weinblatt ME, Setoguchi S, Levin $\mathrm{R}$, et al. Immunosuppressive medications and hospitalization for cardiovascular events in patients with rheumatoid arthritis. Arthritis Rheum 2006;54:3790-8.

47. Widdifield J, Paterson JM, Bernatsky S, Tu K, Tomlinson G, Kuriya $\mathrm{B}$, et al. The epidemiology of rheumatoid arthritis (RA) in Ontario, Canada. Arthritis Rheum 2014;66:786-93.

48. Dejaco C, Duftner C, Wipfler-Freissmuth E, Weiss H, Schneider T, Schirmer M. Elderly- versus younger-onset rheumatoid arthritis: higher levels of ultrasound-detected inflammation despite comparable clinical disease activity. Arthritis Care Res 2013;65:304-8.

49. Schmajuk G, Schneeweiss S, Katz JN, Weinblatt ME, Setoguchi S, Avorn J, et al. Treatment of older adult patients diagnosed with rheumatoid arthritis: improved but not optimal. Arthritis Rheum 2007;57:928-34.

50. Huscher D, Sengler C, Gromnica-Ihle E, Bischoff S, Eidner T, Ochs $\mathrm{W}$, et al. Clinical presentation, burden of disease and treatment in young-onset and late-onset rheumatoid arthritis: a matched-pairs analysis taking age and disease duration into account. Clin Exp Rheumatol 2013;31:256-62. 